The bold items in the margin describe the subject matter and are keywords for text retrieval. The final reference number under each abstract is also used for this purpose (see reprint service on $p$. 184)

\author{
Spam, EU Directive, \\ Information \\ Commissioner, \\ Guidance Notes, \\ opt-in
}

\section{Article Abstracts}

Each abstracted article is awarded 0-5 stars for each of four qualities:

(1) depth of research

(2) value in practice

(3) originality of thinking

(4) readability for non-specialists.

No abstract is included for any article awarded less than seven stars overall.

\section{Electronic marketing and the new anti-spam regulations}

\section{E. Nettleton}

EXPLANATORY. Journal of Database Marketing and Customer Strategy

Management (UK), Vol. 11, No. 3, p. 235 (6pp)

Notes the Directive on Privacy and Electronic Communications, implemented by UK legislation in December 2003, covering direct marketing by phone, fax and electronic communications, subscriber directories, cookies and value-added services which rely on traffic or location data. Notes also the issue of Guidance Notes by the Information Commissioner. Notes that electronic mail must not disguise the identity of the sender, and must provide a valid opt-out address, but that the remaining requirements apply only to unsolicited communications sent to individual persons. Discusses the meaning of 'solicited': either positive consent must have been given, or a 'soft opt-in' (ie details were obtained during negotiations for a sale, and marketing is for similar products/ services and the recipient has been given the opportunity to refuse further use of details and has not done so). Covers the distinction between 'individual' and 'corporate' addressees: the former covers sole traders and partnerships (except in Scotland); the latter includes named persons at corporate addresses. Notes that lists legally compiled before December 2003 can be used, but suggests subsequent lists cannot, except in very rare circumstances. Gives some practical suggestions for compliance. Recognises that spam accounts for 50 per cent of all e-mail, and that the vast majority comes from Asia and the USA, which cannot be prevented by European legislation. Notes the arrival of federal US legislation, and some state laws - but mostly based on an opt-out principle. Notes also that legislation in some EU states is stricter than in the UK.

This legislation, clearly outlined here, will not greatly ease the problem of spam for recipients, but will complicate life for all e-mail marketers.

Research: $* * \quad$ Practice: $* * *$ Originality: $* \quad$ Readability: $* * *$

Ref: 6201 


\section{Data protection,} DPAs, EU, FEDMA

\section{Closing the data door}

A. Tempest

LAW REPORT. Direct Marketing International (UK), May 2004, p. 36 (2pp)

Reports on a meeting in February 2004 of EU national data protection authorities (DPAs) which issued an opinion on 'unsolicited communications for marketing purposes', concentrating on electronic communications. Notes that this meeting is an official committee of the EU Commission. Records the restrictive nature of the opinion in interpreting the terms of the 2002 Directive on E-communications, with particular reference to definitions of consent, the length of time for which it is valid and its non-transferability. Recognises that the opinion is not binding (yet), but holds that it confirms FEDMA's worst fears about the likely activities of this committee. Refers to the FEDMA code, negotiated with the DPAs and adopted in 2003. Additionally notes a number of international developments with legal implications, including call-centre outsourcing, US anti-spam activity and the South African Lotteries Act.

A useful commentary on the unending jousting FEDMA is obliged to conduct with the EU bureaucracy.

Research: $* * \quad$ Practice: $* * \quad$ Originality: $* \quad$ Readability: $* * *$ Ref: 6202

\section{Defining business-to-consumer relationships: The consumer's perspective}

P. Sorce and K. Edwards

RESEARCH. Journal of Database Marketing and Customer Strategy

Management (UK), Vol. 11, No. 3, p. 255 (13pp)

Sets out to explore how consumers define the meaning of a relationship with a commercial firm. Notes in the existing literature a distinction between business marketing relationships (a feature of B2B marketing), interpersonal commercial relationships (between a service firm and its customers) and B2C relationships (defined as the largely technologydriven interaction between a business and an individual customer). Notes that there is sparse literature on this last: most relationship marketing theory derives originally from B2B. Notes others' questioning of whether this transfer from B2B to B2C is valid, either generally or only for highinvolvement products with inelastic demand. Describes a survey conducted with 167 members of faculty and staff of a large US university, who were asked to state what a 'relationship' with a commercial firm meant to them. Describes coding of the responses into 21 constructs, of which the three most frequent were empathy, duration of interaction and responsiveness. Notes that less than 3 per cent of responses mentioned special treatment or loyalty reward programmes. Calls for further research. Concludes customers want firms to know their needs, not to know them personally: 'Friendliness is expected, but friendship is not required.' 
Uses academic methodology to tell us what common sense, and our own experience as consumers, should have told us all long ago. Alas, our industry appears to be short on common sense, and to leave its own experiences outside the office door.

Research: $* * *$ Practice: $* * \quad$ Originality: $* * \quad$ Readability: $* *$ Ref: 6203

The integration of direct marketing and field sales to form a new B2B sales coverage model

J. M. Coe

ANALYTICAL. Journal of Interactive Marketing (US), Vol. 18, No. 2, p. 62 (11pp)

Notes the prevalence of static sales revenues and growing selling costs in today's B2B environment. Draws attention to declining average sales calls per year and growing cost per call. Claims a new sales coverage model is needed, involving a reorganisation of sales and marketing functions around the four targetable contact media - e-mail, telephone, direct mail and face to face. Suggests direct marketing should become a sales tool not just a means of acquiring leads. Advocates a five-step process to reach this new sales coverage model. Demands quantification of cost of enquiries; conversion rate to leads; cost of qualified leads; lead conversion rate; sales calls per period; percentage of calls by type; cost of a call; number of calls per sale; cost of a sale; win rate; customer decay rate; percentage of revenue spent on sales and marketing. Suggests the proportion of time spent on each of customer acquisition, growth, loyalty and reactivation that should be handled by sales or by marketing activity.

The picture conveyed here of the state of development of B2B sales and marketing functions is horrifying; the prescriptions are sound enough what is alarming is that they should be found necessary.

Research: * Practice: $* * *$ Originality: $* * \quad$ Readability: $* * *$ Ref: 6204

\section{Corporate branding for small to medium-sized businesses - A missed opportunity or an indulgence?}

\section{Inskip}

SURVEY. Journal of Brand Management (UK), Vol. 11, No. 5, p. 358 (8pp)

B2B, SMEs, corporate branding
Notes that corporate branding, both as a philosophy of organisational change and as a process, is well understood in a B2C context. Maintains that this is much less common in $\mathrm{B} 2 \mathrm{~B}$ - even among large companies and that the concept is even less well understood among SMEs in this sector. Summarises observations made from interviews with 15 CEOs of SMEs in B2B. Notes that for most corporate branding was a radically new concept: CEOs' attention was on the product, service or technology being sold; few organisations had a marketing department. Emphasises that corporate branding is not just a logo and headed notepaper; dwells on the 


\section{Low-price competition, branding}

Internet, revenue generation, disintermediation, cost reduction, strategic partnerships, media integration need for external help in determining what message an SME might want to portray. Notes the lack of any adequate training in the UK:

BusinessLink at the DTI is too theoretical; the IoD and the CIM both seem to regard branding as applying solely to products. Gives three brief case histories of CEOs of SMEs facing these issues. Examines the subject from the angle of the branding industry; considers the particular problems for large consultancies in dealing with SMEs. Concludes that these need a process that is fast, flexible and focused, with little internal consultation or research.

A clear, straightforward exposition of theme and problems. The issue of corporate branding for any size of company, whether $B 2 B$ or $B 2 C$, is thrown into ever sharper focus by the necessity for good website design.

Research: $* * *$ Practice: $* * * *$ Originality: $* * \quad$ Readability: $* * * *$ Ref: 6205

\section{How to keep low-price competition in check}

\section{S. Butcher and B. Kalsi}

ANALYTICAL. Admap (UK), July/August 2004, p. 18 (4pp)

Notes the dangers to branded-goods manufacturers from low-price competition, and the efforts of a number of suppliers to fight this off by creating a second brand to take on the competition without cannibalising or downgrading the main brand. Instances the case of Sony, spawning Aiwa to compete with Alba; First Direct as an offshoot of HSBC; bmibaby by British Midland. Looks at the issue of differentiation in price and quality; considers the pros and cons of using a separate brand identity versus sheltering under the parent brand; indicates the likely areas of applicability of either strategy, and the influence of geographical factors in the decision.

A clear and interesting exposition.

Research: *** Practice: $* *$ Originality: $* *$ Readability: $* * * *$ Ref: 6206

\section{The evolving role of the internet in marketing strategy: An} exploratory study

F. Sultan and A. J. Rohm

RESEARCH. Journal of Interactive Marketing (US), Vol. 18, No. 2, p. 6 (14pp)

Looks at the findings of two surveys conducted in 2000 and 2002 to compare and contrast the developing attitudes of the participants towards the internet over time. Uses interviews conducted with executives at three firms competing in different industries, in both years. Notes a number of significant changes: the prime emphasis on the use of the internet for revenue generation has changed to one of cost reduction; a drive for disintermediation has given way to the formation of strategic partnerships; more attention was being paid in 2002 to media integration 
in branding and communication. Looks at expected future developments such as CRM and SMS. Discusses drivers of these changes, current and future. Suggests four findings from this longitudinal study: the need for firms to learn over time, and to alter strategies flexibly; the need to recognise that the internet is much more than an e-commerce medium; the need for channel integration; the need to recognise and address the hurdles of intra-organisation politics.

An interesting look at the development of attitudes to the internet in preand post-dot.com bubble days.

Research: $* * *$ Practice: $* *$ Originality: $* *$ Readability: $* * *$ Ref: 6207

\section{Hardball, softball, Toyota, Dell, Wal-Mart}

Internal markets, BP, transfer pricing

\section{Hardball: Five killer strategies for trouncing the competition}

\section{G. Stalk Jr and R. Lachenauer}

HORTATORY. Harvard Business Review (US), April 2004, p. 62 (9pp)

Contrasts the current preoccupations and literature of management science ('softball', concerned with 'squishy' issues such as employee empowerment and customer care) with the examples set by Toyota, Dell and Wal-Mart - 'hardball' players who are destroying their competitors. Insists that playing hardball is not about illegality or cheating, but about determination to win, within the rules. Unveils a hardball manifesto with five counts: focus relentlessly on competitive advantage; strive for extreme competitive advantage; avoid attacking directly; exploit people's will to win; know the caution zone. Follows this with five strategies: devastate rivals' profit sanctuaries; plagiarise with pride; deceive the competition; unleash massive and overwhelming force; raise competitors' costs. Discusses each manifesto point and each strategy, with examples.

An attempt to reverse the trend of current management studies. As with most aggressive theses, truth must surely lie somewhere in the middle.

Research: $* * \quad$ Practice: $* * \quad$ Originality: $* * \quad$ Readability: $* * * *$ Ref: 6208

\section{Bringing the market inside}

T. W. Malone

Suggestive. Harvard Business Review (US), April 2004, p. 107 (8pp)

Contrasts the traditional, hierarchical method of internal decision making within a company (on such matters as allocation of resources) with the novel possibility of constructing an internal market to make the decisions automatically. Gives example of BP which, having set a target in 1998 for the reduction of carbon emissions, created an internal trading system in emission rights among its business units (similar to the international trading system in the Kyoto Protocol). In 2001 this system traded rights in 4.5 million tonnes of carbon emission at an average price of $\$ 40$ per tonne - and BP met its target, nine years ahead of schedule. Notes that traditional transfer pricing is a long-established crude form of internal 


\section{Loyalty, coalitions, smart cards, RFIDs, points auctions}

market, but that new technology, especially the internet, opens up much wider possibilities. Discusses experimental concepts for trading in ideas, and in information. Claims the benefits of an internal market are efficiency (the market makes better decisions than management), freedom, flexibility and motivation. Discusses possible limitations and downsides.

A fascinating description of how Adam Smith's 'hidden hand' can be superior to managerial judgment and diktat. (Try the author's book The Future of Work, Harvard Business School Press 2004.)

Research: $* * \quad$ Practice: $* * \quad$ Originality: $* * * *$ Readability: $* * *$ Ref: 6209

\section{Loyalty trends for the 21 st century}

M. Capizzi, R. Ferguson and R. Cuthbertson

ANALYTICAL. Journal of Targeting, Measurement and Analysis for

Marketing (UK), Vol. 12, No. 3, p. 199 (14pp)

Claims that loyalty marketing now has the characteristics of a mature market, and is approaching saturation. Notes the ubiquity of such schemes, with the USA having four loyalty memberships per adult, but with under 25 per cent of registered members being active over the past 12 months. Notes the spread of 'coalition' loyalty schemes - now the dominant model outside the USA. Predicts rise of more niche coalition programmes. Discusses the need for imagination in the design of schemes - the use of smart cards, of radio-finding identification devices (RFIDs) (whose basic advantage is that an RFID-enabled card can be accessed over a short distance without contact), iris scanning, fingerprinting, electronic tagging of merchandise, wireless shopping assistants, etc. Notes high levels of consumer boredom with loyalty programmes, and the difficulty of telling one programme from another. Emphasises the need for a wow factor, using lifestage or lifestyle-themed rewards of a highly aspirational nature. Discusses loyalty points auctions. Suggests 'soft' benefits are harder for competitors to copy, thus providing differentiation. Emphasises the need for customer data analytics; asserts the loyalty marketing database will be the fuel to power the CRM engine. Foresees a renaissance of loyalty schemes, based on coalitions, imaginatively used technology, wow factor and financial judgment based on data analytics. Gives real-life examples throughout.

An interesting look at the current position and possible future development of loyalty schemes, and at the desiderata for a successful scheme. But lacks any preliminary analysis of just what such schemes, either in general or in particular cases, are intended to achieve.

Research: $* * \quad$ Practice: $* * * *$ Originality: $* * * *$ Readability: $* * *$ Ref: 6210 
CRM, loyalty, retail, segmentation

\section{Customer service, CRM}

\section{The role of CRM within retail loyalty marketing}

$R$. Cuthbertson and A. Laine

RESEARCH. Journal of Targeting, Measurement and Analysis for

Marketing (UK), Vol. 12, No. 3, p. 290 (15pp)

Aims to show how retailers' loyalty strategies influence CRM activities, and to show the role of CRM within loyalty marketing. Reveals research consisting of interviews with 16 leading European (but heavily UKbased) retailers across six product sectors. Notes the value of a loyalty programme as providing real data on what customers do - often different from what they say. Considers, in order to structure interview responses, four key perspectives on CRM: the customer perspective; the internal perspective; the learning and growth perspective; and the financial perspective. Notes that most customer analysis is carried out at a group level, even where communication is tailored to the individual; also that segmentation, mostly at the level of 10-100 segments, takes preference over one-to-one marketing. Notes that loyalty schemes appear to approach breakeven when turnover increases by around 3-4 per cent, but that some retailers (eg Safeway) regard loyalty schemes as too expensive. Notes the difficulty of separating out costs. Distinguishes five different loyalty strategies, described as pure, push, pull, purchase and purge. Provides illustrations of the relative strengths and weaknesses of each strategy, and discusses the differing role of CRM in relation to each strategy.

An interesting and worthwhile discussion of different strategies and their implications, albeit built on slender research foundations.

Research: ** Practice: $* * *$ Originality: $* *$ Readability: $* * *$ Ref: 6211

\section{Why we need freedom from command and control \\ J. Seddon}

DiDACTIC. Customer Management (UK), March/April 2004, p. 10 (4pp)

Maintains that customer service is poor and costs are rising; attempts at improvement, including CRM, fail more often than not. Holds that this is because our theory of the organisation - a command-and-control model introduced by Henry Ford - is faulty. Advocates the abandonment of command and control in favour of systems thinking which works outsidein - starting with customer demand rather than product availability. Notes that 50-70 per cent of the demand for service stems from failures of the system. Deplores the cost-based approach to customer service, and traditional measurement methods such as number of calls handled per person/hour, which stifle the ability of staff to provide service to customers. Stigmatises such management 'fads' as CRM, Six Sigma, customer care training, ISO 9000, EFQM Excellence, CCA Best Practice Standard. Demands a counter-cultural change in management thinking.

An all-too-short statement of what ought to be (but clearly are not) some 


\section{Customer care, loyalty, banking}

self-evident, universally observed truths. The subject deserves more extended chapter-and-verse treatment.

Research: * Practice: $* * *$ Originality: ** Readability: *** Ref: 6212

\section{Electronic customer care: The innovative path to e-loyalty}

S. M. Salmen and A. Muir

THEORETICAL. Journal of Financial Services Marketing (UK), Vol. 8, No. 2, p. 133 (12pp)

Notes that structural changes in the banking sector have resulted in much greater customer choice; this in turn has produced a price-induced reduction in customer loyalty. Recommends the 'individualisation of customer relations' as a way of preventing ruinous price competition. Observes that there are two approaches to earning customer loyalty: locking in, by creating barriers to change, and the creation of customer satisfaction; the former leads to reluctant, behavioural loyalty, and the latter to affirmative loyalty. Claims that financial service providers which are competitively weak tend to grasp at locking in, which is viewed negatively by the customer. Holds that the best strategy is to aim for core affirmative loyalty, using barriers to change only as a strategic additional element. Describes a survey conducted among 45 bankers from Germany, Austria, Switzerland and the USA to explore the question of whether electronic customer care (ECC) tools can promote the individualisation of customer-bank relations, and which tools are best suited for the creation of long-term customer loyalty. Recommends the use of ECC to create personalised websites for selected customers - concentrating on the new generation of affluent private customers. Recommends self-customised push-based services to increase customer usage, including individual push-based price differentiation - either supplier- or customer-driven.

This interesting look at potential one-to-one relationships in banking is marred by being apparently not very well translated from an original German text, rendering its structure and message unduly opaque. But worth struggling with.

Research: ** Practice: $* * *$ Originality: $* * *$ Readability: $* *$ Ref: 6213

\section{A database approach to cross-selling in the banking industry: Practices, strategies and challenges}

K. Lau, H. Chow and C. Liu

PRAGMATIC. Journal of Database Marketing and Customer Strategy Management (UK), Vol. 11, No. 3, p. 216 (19pp)

Lists the primary goals of a bank as cross-selling; retention; increasing utilisation; acquisition; cost/service quality. Sets out to examine crossselling in the context of Hong Kong banking. Delineates two possible approaches, described as active and passive selling. The former involves 
either product-based campaigns (selling specific products, by direct mail or outbound telemarketing, to as many customers as possible) or customer-based marketing (making event-triggered or profile-triggered approaches to specific customers offering product(s) to meet their ascertained needs). Notes that direct mail response rates have been declining for years (credit card mailings now pull 0.6 per cent versus 2.8 per cent four years ago), due to 'abusive' levels of direct mail in circulation. Discusses the use of data-mining technology; notes the danger of using precise mathematical techniques on imprecise, uncleansed, outdated data, and of 'getting an exact solution to the wrong question'. Looks at event-triggered selling, starting with birthday programmes, but extending to other events via a variety of both external and internal data: discusses methods of data capture. Discusses profiletriggered marketing, using product bundling; notes the problems caused here by banks' organisation in product silos. Discusses passive selling ie using customer calls, in the branch or by telephone, as opportunities for cross-selling. Indicates this requires a computer-generated next-productto-offer (NPO) to be prepared in advance and made available to customer service staff. Discusses future trends and strategy. Emphasises the need for data integrity and internal structural change.

There is nothing very new in all this (apart from some eye-opening revelations on data availability in $\mathrm{HK}$ ). But it is expressed with great clarity and logical structure and is well worth reading.

Research: * Practice: $* * * *$ Originality: $* \quad$ Readability: $* * * * *$ Ref: 6214

\section{Gender, financial services}

\section{Cyber dudes and cyber babes: Gender differences and internet financial services}

A. Maltby, F. Chudry and G. Wedande

EXPLORATORY. Journal of Financial Services Marketing (UK), Vol. 8, No. 2, p. 152 (14pp)

Recalls earlier studies of gender differences in the processing of financial services direct mail solicitations. Aims to examine if similar differences apply in financial decision making on the web. Notes gender differences revealed by other studies in internet use. Relates the structure of a twopart study: the first part consisted of an online questionnaire completed by 481 persons (heavily biased towards 18-29-year-olds). This was devoted to obtaining an understanding of people's internet usage - frequency, purposes, increase/decrease, reaction to symbols, personal data gathering, etc. The second part consisted of four focus groups involving 12 men and eight women, who visited three pre-selected websites (for an internet bank, a mortgage lender and an equity bond) and discussed their experiences. Describes in detail the quantitative and qualitative findings. Concludes that, in contrast to previous direct mail findings, there is little gender difference in reactions to web design: both sexes were concerned about fast download, ease of navigation and up-to-dateness. 


\section{Financial services, consumer dissatisfaction}

An interesting subject, vitiated by a poorly structured test. Moreover, the differences being sought may have been overwhelmed by much more obvious deficiencies in the sites examined.

Research: ** Practice: $* \quad$ Originality:** Readability: $* *$ Ref: 6215

\section{Consumer responses to dissatisfaction with financial service providers: An exploration of why some stay while others switch} T. Panther and J. D. Farquhar

EXPLORATORY. Journal of Financial Services Marketing (UK), Vol. 8, No. 4, p. 343 (11pp)

Claims that most research in customer dissatisfaction has centred on products, although services create more dissatisfaction; in particular, those who exhibit 'loyalty' by staying with their service provider despite dissatisfaction have been little researched - only complaint behaviour has been considered. Notes that customer loyalty generally is stronger towards service than product providers - no doubt because services are bought with a view to a future stream of activities rather than as a discrete transaction. Describes a two-stage research design, of which stage one was an eight-person focus group which, in discussing the issues involved, led to the structure of a self-completion questionnaire for which 81 responses were eventually obtained. Indicates that 30 per cent of the sample left their supplier after dissatisfaction; 70 per cent did not. The reasons had to do with 'hassle', tradition, complexity, time shortage, alternatives equally bad. Concludes that perceived switching costs were the main component in the decision by dissatisfied customers to stay. Considers implications for those wishing to entice customers away from competitors. Discusses plans for further research.

A decidedly unstartling set of findings.

Research: $* * *$ Practice: $* *$ Originality: $*$ Readability: $* * *$ Ref: 6216

\section{So that's your aptitude?}

\section{S. Cook}

JouRnALISTIC. Management Today (UK), April 2004, p. 50 (4pp)

\section{Recruitment, psychometric testing}

Notes the growth (over ten years) in the use of psychometric tests in staff selection: suggests 70 per cent of blue-chip organisations now use them at all levels. Indicates that such tests can save considerable money on recruitment costs. Asks whether they also improve the quality of recruitment, and finds that a combination of cognitive ability tests, work sample tests and structured interviews achieve the best results. Indicates that psychometric tests should not be used in isolation; one authority would give them 60 per cent of the decision-making function, another 20 per cent. Holds that such tests should only be given by trained personnel. 
Quotes from the (mostly positive) experiences of three employees who have taken psychometric tests.

The article fails to distinguish between tests (eg IQ tests) which ask candidates to choose the right answers to intelligible questions, and tests where any answer can be made to fit the prejudices of the presiding psychologist. The former type is legitimate, the latter gobbledegook.

Research: ** Practice: $* *$ Originality: $*$ Readability: $* * *$ Ref: 6217

\section{Stars, recruitment, Wall Street}

\section{China, GDP, WTO}

\section{The risky business of hiring stars}

B. Groysberg, A. Nanda and N. Nohria

ANALYTICAL. Harvard Business Review (US), May 2004, p. 92 (9pp)

Notes that human resources experts have rarely studied the performance of star employees over time. Observes that top performers in a wide range of posts are more like comets than stars: they blaze briefly and quickly fade when changing employer. Describes a methodology employed for examining this phenomenon in the context of 1,052 star stock analysts in the USA working for 78 investment banks. Notes that their performance is independently ranked on Wall Street; that they suffer little change in their personal circumstances when they move company; and that it is commonly believed that their performance is wholly dependent on talent - it therefore follows that if their performance is not portable, then probably other executives' performance is not portable either. Examines typical outcomes when stars move: their lustre fades; group performance in their new company slips; company valuation suffers. Quotes instances. Considers the drivers of star performance: resources, systems, leadership, internal networks, training, teams. Recommends growing rather than hiring stars. Provides instructive examples of different types of recruitment in action.

To be read and pondered by anyone involved in recruitment policy at anything other than initial employment level. Together with the thought that the company most devoted to the policy of hiring stars was of course Enron.

Research: $* * * *$ Practice: $* *$ Originality: $* * * *$ Readability: $* * * * *$ Ref: 6218

\section{China dreams}

H. Davies and L. Yueh

JouRnALISTIC. Management Today (UK), March 2004, p. 44 (6pp)

Notes that the Chinese economy will probably be larger than the UK's by the end of 2005; average growth since 1989 has been 9 per cent per annum, with an investment rate of 35 per cent of GDP (double the UK rate). Exports are up by five times in 15 years, and GDP per head by ten times in 20 years. Notes the existence of serious problems, especially the inefficient state-owned enterprises which are still huge employers, and a 


\section{Advertising, prescription medicines, DTCA, New Zealand, USA}

banking system overloaded with non-performing loans (comparable with a decade-long problem in Japan). Indicates that the normal legal underpinnings (property and contract law) of a capitalist system are largely lacking, while accounting standards are poorly enforced. Notes that China's accession to the WTO will compel changes towards transparency. Questions the availability of capable managers below the elite level. Notes that the UK insurance industry is making inroads in China, and that Hong Kong, no longer a political liability, acts as a bridge for UK trade. Notes that in 2003 the UK welcomed more Chinese students than the USA. Gives brief case studies of the China Development Bank, and of Prudential and Exel in China.

A quick look at the world's biggest growth market - its upside and its downside.

Research: $* * *$ Practice: $* \quad$ Originality: $* * \quad$ Readability: $* * *$ Ref: 6219

\section{Direct-to-consumer advertising of prescription medicines in the United States and New Zealand: An analysis of regulatory approaches and consumer responses \\ J. Hoek, P. Gendall and J. Calfee}

SURVEY. International Journal of Advertising (UK), Vol. 23, No. 2, p. 197 (12pp)

Takes further the debate covered in Vol. 23, No. 1 (see the article abstracted in our last issue, ref. 6105). Notes the very different economies and healthcare systems of the USA and New Zealand. Suggests that direct-to-consumer advertising (DTCA) of prescription medicines happened in each through a legislative loophole. Notes and compares the different forms of regulation applied to DTCA in each country, including a notable degree of self-regulation in New Zealand. Notes a level of opposition to DTCA among doctors and consumers in both countries. Gives the results of three consumer surveys - one in New Zealand (2002) and two in the USA (2001 and 2002): these show high levels of awareness and an overall view that DTCA is helpful; Americans recalled information on risks and side-effects more readily than New Zealanders. Concludes that these results provide no support to those calling for a ban on DTCA, and suggests public policy should be guided by careful research and not by small pressure groups.

An interesting look at a subject that could become relevant in the EU at some future date.

Research: $* * *$ Practice: $* \quad$ Originality: $* * \quad$ Readability: $* * *$ Ref: 6220 


\section{IMC, transactional data, relational data}

\section{Perceptions of IMC after a decade of development: Who's at the wheel and how can we measure success?}

W. N. Swain

THEORETICAL. Journal of Advertising Research (UK), Vol. 44, No. 1, p. 46 (20pp)

Notes the development of the concept of integrated marketing communications (IMC) since the early 1990s. Concentrates on three questions held to be relevant to a workable definition and theoretical construct of IMC: how should it be led within a firm; how should its success be measured; what is an appropriate method of agency compensation in the context of IMC? Discusses each of these issues. Sets out to examine whether a consensus exists among practitioners and academics on these subjects. Describes a survey, conducted by a selfadministered questionnaire, of 185 such persons asked to choose from a selection of answers to these questions. Tabulates answers given, with cross-tabs by sub-group. Finds that there is little agreement among respondents on any of these issues, and concludes from this that IMC is not yet a cohesive and effective paradigm, theory or practice, and will become so only when theoreticians and practitioners can develop a consensus on these matters.

That we should all aspire to integrated marketing communications is a matter of mere common sense; that we need to create, define and theorise about another monstrous acronym called IMC (is the CRM catastrophe not enough yet?) is surely more debatable.

Research: **** Practice: $* *$ Originality: $* \quad$ Readability: $* * *$ Ref: 6221

The role of transactional versus relational data in IMC programmes: Bringing customer data together

D. Zahay, J. Peltier, D. E. Schultz and A. Griffin

THEORETICAL. Journal of Advertising Research (UK), Vol. 44, No. 1, p. 3 (16pp)

Notes the explosive growth in electronic media and its effect on advertisers' view of integrated marketing communications (IMC). Contrasts the traditional exchange-oriented model of marketing, viewed as a series of discrete transactions, with relationship marketing based on developing customer retention and loyalty. Categorises these two approaches as deriving from, respectively, a sales-oriented and a marketing-oriented organisation. Emphasises the need for crossfunctional information flows that make available both transactional data collected by sales and relationship data collected by marketing; claims that in practice this is often inhibited by intra-organisational conflict between sales and marketing. Discusses the nature of sales orientation and of marketing orientation, and the types of data that each can produce; suggests that transactional and relational data lie not at opposite poles but scattered along a continuum. Develops a series of hypotheses, claiming that growth on both transactional and relational data will enhance both 
Transactional data, low-value customers

\section{Geodemographics, 2001 Census}

sales and marketing performance; that improved data quality will add to this effect; that relational data have greater effect than transactional data. Describes a survey of 209 software and insurance marketing executives operating in a B2B context, which confirms these hypotheses.

Somewhere in this wordy piece there lurks a short, sensible message. The obligatory academic survey and analysis is deeply unconvincing, despite the prima facie reasonableness of the hypotheses it sets out to validate.

Research: $* * \quad$ Practice: $* * \quad$ Originality: $* \quad$ Readability: $* *$ Ref: 6222

\section{Drilling down into data}

R. Scase

DiDACTIC. Brand Strategy (UK), June 2004, p. 50 (2pp)

Maintains that marketers are still too reliant on one-off transactional data, and thus fail to recognise the future potential spending of today's 'lowvalue' customers. But commends Tesco as an example of how even transactional data can be mined to reveal customer potential; holds that longitudinal measurement over time is the only way to build up a true customer picture. Illustrates a 25 -year decline in brand loyalty across all age ranges, and a corresponding rise in the need for new experiences. Urges the need for management to delegate more responsibility to frontline staff for reporting on consumer habits. Notes the increasing discrimination of consumers, and questions the future ability of marketing to shape their decision making as it did ten years ago.

An interesting collection of snapshots.

Research: * Practice: $* * \quad$ Originality: $* \quad$ Readability: $* * *$

Ref: 6223

\section{An introductory review of geodemographic information systems} P. Sleight

EDUCATIONAL. Journal of Targeting, Measurement and Analysis for Marketing (UK), Vol. 12, No. 4, p. 379 (10pp)

Considers why most users of geodemographics make use of the neighbourhood classifications of such systems as ACORN or MOSAIC, rather than working with the raw data; concludes this is because neighbourhood classifications offer the invaluable facility of profiling. Illustrates what this means and how it works. Describes how neighbourhood classifications are constructed. Describes the nature of Census data - especially the output areas (OAs) used in the 2001 Census. Emphasises the nature of neighbourhood information - that it is statistical data about an area, not factual data about particular persons or families. Relates the 'birds of a feather' concept that underlies the use of neighbourhood data. Describes the make-up of Census area statistics (CAS data). Describes the way in which CAS data are used to produce a 
neighbourhood classification. Describes the method of linking addresses to Census areas (much simplified and improved in the 2001 Census).

This article is based on Chapter 3 of the author's book Targeting Customers, revised for the release of the 2001 Census and reviewed in this issue. For those who want to understand the concept of geodemographics, a clearer exposition could hardly be looked for.

Research: $* * *$ Practice: $* * * * *$ Originality: $* * * *$ Readability: $* * * * *$ Ref: 6224 